\title{
UTERINE FIBROIDS
}

Uterine Leiomyoma, Leiomyomata, , Myoma, Fibromyoma, Fibroleiomyoma

The most common benign smooth muscle tumors of the uterus encountered in women of reproductive age.

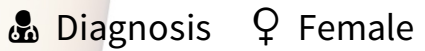

\section{Related Diagnoses:}

Obesity | Menstrualcycle disorders | Fallopian tube blockage | Endometriosis | Adenomyosis Menopause | Amenorrhoea | Oligomenorrhea Hypoestrogenism | Recurrentmiscarriage $\mid$ Hysterectomy

\section{i About Uterine fibroids}

Uterine fibroids are a major cause of morbidity in women of a reproductive age. About $20 \%$ to $80 \%$ of women develop fibroids by the age of 50 . After menopause they usually decrease in size. The exact cause is unclear. Typically, fibroids appear as well-defined, solid masses with a whorled appearance (Pic. 1). Uterine fibroids grow from the uterine muscle and are under the hormonal influence of estrogen, that is why they do not exist before the secretion of this hormone before puberty, and they regress with menopause. Cancerous versions of fibroids are very rare and are known as leiomyosarcomas. They do not appear to develop from benign fibroids. However, for some women, fibroids can significantly affect their quality of life. Most fibroids do not require treatment unless they are causing symptoms. After menopause fibroids shrink and it is unusual for them to cause problems. In those who have symptoms the treatment modality is primarily surgical and herbal preparations are commonly used as alternatives to surgical procedures. Uterine fibroids are leiomyomata of the uterine smooth muscle. As other leiomyomata, they are benign, but may lead to excessive menstrual bleeding (menorrhagia), often cause anemia and may lead to infertility.

Fibroids are categorized into three groups according the place on which they appear:

1. Submucosal fibroids growing in the uterine cavity.

2. Intramural fibroids growing in the wall of the uterus.

3. Subserosal fibroids growing on the outside of the uterus. 
Diagnosis may occur by pelvic examination or medical imaging. While a bimanual examination typically can identify the presence of larger fibroids, gynecologic ultrasonography (ultrasound) has evolved as the standard tool to evaluate the uterus for fibroids. Polyps may be better visualized during saline infusion sonohysterography, in which the saline pushes apart the uterine cavity, and the polyps appear as smoothly margined focal lesions that protrude into the endometrial cavity (Pic. 2). Also magnetic resonance imaging (MRI) can be used to define the depiction of the size and location of the fibroids within the uterus. Imaging modalities cannot clearly distinguish between the benign uterine leiomyoma and the malignant uterine leiomyosarcoma, however, the latter is quite rare.

Other imaging techniques that may be helpful specifically in the evaluation of lesions that affect the uterine cavity are hysterosalpingography or sonohysterography.

\section{Associated diseases}

- $\quad$ subfertility

- anemia

- ectopic pregnancy

- menopause

- uterine cancer

- miscarriage

- narcolepsy (a chronic neurological disorder involving the loss of the brain's ability to regulate sleep-wake cycles normally)

\section{Complications}

Complications can arise from the location of the fibroids. These complications range from intermittent bleedings to continuous bleeding over weeks, from single pain episodes to severe menorrhagia and chronic abdominal pain with intermittent spasms, from dysuria and constipation to chronic bladder and bowel spasms and even to peritonitis. Infertility may be the result of continuous metro- and menorrhagia, leading to chronic infection and uterine spasms up to nonimplantation. Possible complications resulting from treatment of these disorders are haemorrhages, infection, adhesions, and secondary pain resulting from the treatment efforts.

\section{Risk factors}

\section{$\underline{\text { Race and age }}$}

The cumulative incidence (based both on ultrasonographic detection of fibroids in women with an intact uterus and evidence of prior fibroids among women who have had hysterectomies) increases with age, but the rate of increase slows at older ages. This suggests that the older premenopausal uterus is less susceptible to fibroid development.

\section{Early menarche}

Early age of menarche is also a risk factor for uterine fibroids and other hormonally mediated conditions such as endometrial and breast cancers. The biological 
mechanisms are not understood, and they may or may not be the same for the different hormonally mediated conditions.

\section{Parity and pregnancy}

Although a direct protective effect of pregnancy has been demonstrated, little is known of the mechanism. There have been some suggestions that during postpartum uterine remodeling, there could be selective apoptosis of small lesions. Ischemia during parturition has also been proposed as a mechanism. Thus, it may be implied that fibroid tissue could be highly susceptible to ischemia during both parturition and remodeling.

\section{Caffeine intake}

Current drinkers had significantly higher risks than women who had never consumed alcohol, and there appears to be a dose response for both duration of alcohol consumption and number of drinks per day. With regards to caffeine, among women $<35$ years of age, the highest categories of caffeinated coffee ( $\geq 3$ cups/day) and caffeine intake ( $\geq 500 \mathrm{mg} /$ day) were both associated with increased fibroid risk.

\section{$\underline{\text { Other possible factors }}$}

There is contemporary interest in the influence of dynamics encompassing the likes of uterine infection, hormonal, metabolic, dietary, stress, and environmental factors. The underlying biological mechanism of infection-related oncogenesis proposed is that injury caused by infection or inflammation proceeds through several possible pathways, leading to increased extracellular matrix, cell proliferation, and decreased apoptosis, apropos of abnormal tissue repair. The upregulation of extracellular matrix proteins that is consistently seen in gene profiling studies of fibroids compared with normal myometrium is consistent with such a mechanism. As luteinizing hormone (LH) shares a receptor with human chorionic gonadotropin, the hormone that stimulates uterine growth during early pregnancy, it is hypothesized that peri-menopausal increases in LH would stimulate fibroid growth. Metabolic factors like diabetes, polycystic ovaries, and hypertension have been examined. Dietary factors have looked at the intake of soy which tends to have anti-estrogenic effects when endogenous estrogens are high (i.e., premenopausal women), thus hypothesizing that soy intake might reduce fibroid risk. A possible mechanism of the impact of stress involves the effects of stress on adrenal activity that could raise progesterone levels, and thus increase fibroid development. All these areas of interest are currently hypothetical and need further study to clarify their exact role in the etiology of fibroids.

\section{Impact on fertility}

Occasionally fibroids may make it difficult to get pregnant although this is uncommon. While fibroids are common, they are not a typical cause for infertility, accounting for about $3 \%$ of reasons why a woman may not be able to have a child. The majority of women with uterine fibroids will have normal pregnancy outcomes. In cases of intercurrent uterine fibroids in infertility, a fibroid is typically located in a submucosal position and it is thought that this location may interfere with the function of the lining 
and the ability of the embryo to implant. Also larger fibroids may distort or block the fallopian tubes.

\section{F Prevention}

- exercise regularly

- manage your weight

Ways to prevent uterine fibroids from forming are mostly unknown. However, specialists have been able to determine some risk factors and treatments that can help in understanding fibroids.

\section{Us Symptoms}

Fibroids, particularly when small, may be entirely asymptomatic. Symptoms depend on the location of the lesion and its size. Important symptoms include abnormal gynecologic hemorrhage, heavy or painful periods, abdominal discomfort or bloating, painful defecation, back ache, urinary frequency or retention, and in some cases, infertility. There may also be pain during intercourse, depending on the location of the fibroid. During pregnancy they may also be the cause of miscarriage, bleeding, premature labor, or interference with the position of the fetus.

\section{(1+1) Therapies}

\section{(1+) Self therapy}

\section{Chinese medicine}

Certain acupuncture points have an affinity to the uterus, so therapy may be managed to the affected area.

Herbal medicine is also very useful for treating fibroids. Chinese herbal medicine may shrink fibroids and relieve fibroid symptoms.

\section{(17) Conventional medicine}

\section{Pharmacotherapy}

A number of medications are in use to control symptoms caused by fibroids. NSAIDs can be used to reduce painful menses.

Oral contraceptive pills are prescribed to reduce uterine bleeding and cramps. Anemia may have to be treated with iron supplementation. 
Levonorgestrel intrauterine devices are highly effective in limiting menstrual blood flow and improving other symptoms. Side effects are typically very moderate because the levonorgestrel (a progestin) is released in low concentration locally. There is now substantial evidence that Levongestrel-IUDs provide good symptomatic relief for women with fibroids. While most Levongestrel-IUD studies concentrated on treatment of women without fibroids a few reported very good results specifically for women with fibroids including a substantial regression of fibroids.

\section{Danazol}

Danazol is an effective treatment to shrink fibroids and control symptoms. Its use is limited by unpleasant side effects. Mechanism of action is thought to be antiestrogenic effects. Recent experience indicates that safety and side effect profile can be improved by more cautious dosing.

\section{Dostinex}

Dostinex in a moderate and well tolerated dosis has been shown in 2 studies to shrink fibroids effectively. Mechanism of action is unclear.

\section{Gonadotropin-releasing hormone analogs}

Gonadotropin-releasing hormone analogs cause temporary regression of fibroids by decreasing estrogen levels. Because of the limitations and side effects of this medication it is rarely recommended other than for preoperative use to shrink the size of the fibroids and uterus before surgery. It is typically used for a maximum of 6 months or less because after longer use they could cause osteoporosis and other typically postmenopausal complications. The main side effects are transient postmenopausal symptoms. In many cases the fibroids will regrow after cessation of treatment, however significant benefits may persist for much longer in some cases. Several variations are possible, such as $\mathrm{GnRH}$ agonists with add-back regimens intended to decrease the adverse effects of estrogen deficiency. Several add-back regimes are possible, tibolone, raloxifene, progestogens alone, estrogen alone, and combined estrogens and progestogens.

\section{$\underline{\text { Ulipristal acetate }}$}

Ulipristal acetate is a synthetic selective progesterone receptor modulator which has been tested in small radomized trials with good results for the treatment of fibroids.Similar to other selective progesterone receptor modulators and antagonists benign histologic endometrial changes were reported and long term safety outside of clinical studies has not been established yet. 
Progesterone antagonists such as Mifepristone have been tested, there is evidence that it relieves some symptoms and improves quality of life but because of adverse histological changes that have been observed in several trials it cannot be currently recommended outside of research setting. Progesterone and the PR (progesterone receptor) may enhance proliferative activity in fibroids. These observations have raised the possibility that antiprogestins and agents or molecules that modulate the activity of the PR could be useful in the medical management of uterine fibroids (Pic. 3). Selective progesterone receptor modulators, such as Progenta, have been under investigation.

\section{Surgical therapy}

When surgery is indicated in cases of myomas, laparoscopic surgery is the primary choice. Preoperative assessment is important to determine the operative strategy according to size, number, and location of the myomas. Precise preoperative diagnosis indicates whether laparoscopic myomectomy is possible or whether laparotomy should be performed for large or numerous myomas. In extreme cases, major surgery can be the best choice to remove fibroids to improve the health of the body.

Surgery may take the form of myomectomy (hysteroscopic, laparoscopic, abdominal and robotic), and hysterectomy (vaginal, abdominal, and laparoscopic).

\section{Assisted reproduction}

Larger fibroids may distort or block the fallopian tubes. In vitro fertilization (IVF) is an alternative treatment to surgical removal in this condition because IVF - ICSI bypass the fallopian tubes. If all efforts to conceive and carry a pregnancy to full term fails, surrogacy may be considered as another option.

\section{Find more about related issues}

\section{هำ Diagnoses}

\section{Obesity}

A disease of excess body fat that can have a negative effect on health, leading to reduced life expectancy and other health problems.

Learn more at: www.fertilitypedia.org/therapy/diag/obesity

\section{Menstrual cycle disorders}

An abnormal condition in a woman's menstrual cycle.

Learn more at: www.fertilitypedia.org/therapy/diag/menstrual-cycle-disorders 


\section{Fallopian tube blockage}

An obstruction prevents the egg or sperm from traveling down the tube, thus making fertilization impossible.

Learn more at: www.fertilitypedia.org/therapy/diag/fallopian-tube-blockage

\section{Endometriosis}

A state in which pieces of the tissue alike to the lining of the uterus (endometrium) grow in other parts of the body.

Learn more at: www.fertilitypedia.org/therapy/diag/endometriosis

\section{Adenomyosis}

Medical condition characterized by the presence of ectopic endometrial tissue within the myometrium. Learn more at: www.fertilitypedia.org/therapy/diag/adenomyosis

\section{Menopause}

The time in most women's lives when menstrual periods stop permanently, and the woman is no longer able to have children.

Learn more at: www.fertilitypedia.org/therapy/diag/menopause

\section{Amenorrhoea}

The absence of a menstrual period in women of reproductive age.

Learn more at: www.fertilitypedia.org/therapy/diag/amenorrhoea

\section{Oligomenorrhea}

Light or infrequent menstrual flow at intervals of 39 days to 6 months or 5-7 cycles in a year.

Learn more at: www.fertilitypedia.org/therapy/diag/oligomenorrhea

\section{Hypoestrogenism}

A lower than normal level of estrogen which is the primary sex hormone in women.

Learn more at: www.fertilitypedia.org/therapy/diag/hypoestrogenism

\section{Recurrent miscarriage}

Three or more consecutive pregnancy losses before 20-24 weeks of gestation or below a fetal weight of $500 \mathrm{~g}$.

Learn more at: www.fertilitypedia.org/therapy/diag/recurrent-miscarriage

\section{Hysterectomy}

A surgery performed to remove a woman's uterus.

Learn more at: www.fertilitypedia.org/therapy/diag/hysterectomy

\section{Organs}




\section{Fallopian tubes}

Two very fine tubes that transport sperm toward the egg, and allow passage of the fertilized egg back to the uterus for implantation.

Learn more at: www.fertilitypedia.org/edu/organs/fallopian-tubes

\section{Myometrium}

The middle layer of the uterine wall, consisting of uterine smooth muscle cells.

Learn more at: www.fertilitypedia.org/edu/organs/myometrium

\section{Uterus}

The uterus is the largest and major organ of the female reproductive tract that is the site of fetal growth and is hormonally responsive

Learn more at: www.fertilitypedia.org/edu/organs/uterus

\section{○ Reproductive cells}

\section{Oocyte}

A female germ cell involved in reproduction.

Learn more at: www.fertilitypedia.org/edu/reproductive-cells/oocyte

\section{Zygote}

The cell formed by the union of a sperm and an oocyte.

Learn more at: www.fertilitypedia.org/edu/reproductive-cells/zygote

\section{Biological control}

\section{Estrogen}

The primary female sex hormone responsible for the development and regulation of the female reproductive system and secondary sex characteristics.

Learn more at: www.fertilitypedia.org/edu/biological-control/estrogen

\section{Luteinizing hormone}

A hormone, that stimulates ovulation and the development of the corpus luteum in females, and the production of androgens in males.

Learn more at: www.fertilitypedia.org/edu/biological-control/luteinizing-hormone

\section{Progesterone}

Steroid hormone, secreted by the ovaries, whose function is to prepare the uterus for the implantation of a fertilized ovum and to maintain pregnancy.

Learn more at: www.fertilitypedia.org/edu/biological-control/progesterone

\section{Reproductive functions}




\section{Fertilization}

The fusion of an ovum with a sperm to initiate the development of a new individual organism.

Learn more at: www.fertilitypedia.org/edu/reproductive-functions/fertilization

\section{Implantation}

The very early stage of pregnancy at which the embryo adheres to the wall of the uterus.

Learn more at: www.fertilitypedia.org/edu/reproductive-functions/implantation

\section{Oogenesis}

The process of the maturation of the female gametes through the meiotic division.

Learn more at: www.fertilitypedia.org/edu/reproductive-functions/oogenesis

\section{Ovulation}

The release of egg(s) from the ovaries.

Learn more at: www.fertilitypedia.org/edu/reproductive-functions/ovulation

\section{A Risk factors}

\section{Alcohol drinking}

A pattern of drinking that results in harm to one's health, interpersonal relationships, or ability to work. Learn more at: www.fertilitypedia.org/therapy/rf/alcohol-drinking

\section{Early onset of menses}

Occurrence of menstruation in 11 years or less.

Learn more at: www.fertilitypedia.org/therapy/rf/early-onset-of-menses

\section{Ectopic pregnancy}

A complication of pregnancy in which the embryo attaches outside the uterus.

Learn more at: www.fertilitypedia.org/therapy/rf/ectopic-pregnancy

\section{Emotional stress}

Learn more at: www.fertilitypedia.org/therapy/rf/emotional-stress

\section{Family history}

A higher risk of disease when multiple family members are affected. Learn more at: www.fertilitypedia.org/therapy/rf/family-history

\section{Low level of estrogen}

A diminished level of blood estrogen level.

Learn more at: www.fertilitypedia.org/therapy/rf/low-level-of-estrogen 


\section{Miscarriage}

Pregnancy loss is the natural death of an embryo or fetus before it is able to survive independently Learn more at: www.fertilitypedia.org/therapy/rf/miscarriage

\section{Narcolepsy}

Narcolepsy is a long-term neurological disorder that involves a decreased ability to regulate sleep-wake cycles.

Learn more at: www.fertilitypedia.org/therapy/rf/narcolepsy

\section{Obesity}

A medical condition of excess body fat that can have a negative effect on health, leading to reduced life expectancy and other health problems.

Learn more at: www.fertilitypedia.org/therapy/rf/obesity

\section{Peritonitis}

An inflammation of the peritoneum, the thin tissue that lines the inner wall of the abdomen and covers most of the abdominal organs.

Learn more at: www.fertilitypedia.org/therapy/rf/peritonitis

\section{Uterine cancer}

Abnormal growth of any cells that comprise uterine tissue.

Learn more at: www.fertilitypedia.org/therapy/rf/uterine-cancer

\section{Uterine fibroids}

Benign smooth muscle neoplasm that very rarely becomes cancer.

Learn more at: www.fertilitypedia.org/therapy/rf/uterine-fibroids

\section{○ Symptoms}

\section{Anemia}

A decrease in number of red blood cells or less than the normal quantity of hemoglobin in the blood resulting in low oxygen levels in body tissues.

Learn more at: www.fertilitypedia.org/edu/symptoms/anemia

\section{Chronic pelvic pain}

Pain in the area of the pelvis, that lasts more than six months.

Learn more at: www.fertilitypedia.org/edu/symptoms/chronic-pelvic-pain-1

\section{Constipation}

A condition where the feces are hardened because of excess water removal in the colon. Learn more at: www.fertilitypedia.org/edu/symptoms/constipation 


\section{Early puberty for girls}

The onset of puberty before the average age in girls (8 years).

Learn more at: www.fertilitypedia.org/edu/symptoms/early-puberty-for-girls

\section{Heavy or prolonged bleeding in menstrual period}

Abnormally heavy or prolonged bleeding in menstrual periods.

Learn more at: www.fertilitypedia.org/edu/symptoms/heavy-or-prolonged-bleeding-in-menstrualperiod-1

\section{Hemorrhage}

The condition in which the blood escapes from the circulatory system.

Learn more at: www.fertilitypedia.org/edu/symptoms/hemorrhage

\section{Infertility}

The failure to achieve a clinical pregnancy after 12 months or more of regular unprotected sexual intercourse.

Learn more at: www.fertilitypedia.org/edu/symptoms/infertility

\section{Infrequent menstruation}

The medical term for infrequent, often light menstrual periods (intervals exceeding 35 days).

Learn more at: www.fertilitypedia.org/edu/symptoms/infrequent-menstruation-1

\section{Irregular bleeding between the menstrual periods}

Bleeding that occurs irregulary between the menstrual period.

Learn more at: www.fertilitypedia.org/edu/symptoms/irregular-bleeding-between-the-menstrual-

periods-1

\section{Narcolepsy}

A chronic neurological disorder which is caused by the brain's inability to control sleep and wakefulness. Learn more at: www.fertilitypedia.org/edu/symptoms/narcolepsy

\section{Painful defecation}

The feel of pain during defecation.

Learn more at: www.fertilitypedia.org/edu/symptoms/painful-defecation

\section{Painful sexual intercourse}

The painful feelings during sexual intercourse.

Learn more at: www.fertilitypedia.org/edu/symptoms/painful-sexual-intercourse

\section{Painful urination}

A burning or stinging sensation during urination.

Learn more at: www.fertilitypedia.org/edu/symptoms/painful-urination-1 


\section{Peritonitis}

An inflammation of the peritoneum, usually caused by an infectious organism that is introduced into the abdominal cavity.

Learn more at: www.fertilitypedia.org/edu/symptoms/peritonitis

\section{Recurrent miscarriage}

A disease distinct from infertility, defined by two or more failed pregnancies.

Learn more at: www.fertilitypedia.org/edu/symptoms/recurrent-miscarriage

\section{(†) Therapies}

\section{Acupuncture}

A form of alternative medicine and a key component of traditional Chinese medicine involving thin needles inserted into the body at acupuncture points

Learn more at: www.fertilitypedia.org/edu/therapies/acupuncture

\section{Egg donation}

Process by which a woman donates eggs for purposes of assisted reproduction or biomedical research. Learn more at: www.fertilitypedia.org/edu/therapies/egg-donation

\section{ICSI}

A micromanipulative fertilization technique in which a single sperm is injected directly into an egg. Learn more at: www.fertilitypedia.org/edu/therapies/icsi

\section{Myomectomy}

The surgical removal of uterine leiomyomas.

Learn more at: www.fertilitypedia.org/edu/therapies/myomectomy

\section{Pharmacotherapy of uterine fibroids}

A treatment using drugs to diminish symptoms, release pain and return balance to hormonal system in case of uterine fibroids.

Learn more at: www.fertilitypedia.org/edu/therapies/pharmacotherapy-of-uterine-fibroids

\section{Physical exercise}

Physical exercise is any bodily activity that enhances or maintains physical fitness and overall health and wellness.

Learn more at: www.fertilitypedia.org/edu/therapies/physical-exercise-1

\section{Sperm donation}

The procedure in which a man (sperm donor) provides his sperm for fertility treatment. Learn more at: www.fertilitypedia.org/edu/therapies/sperm-donation 


\section{Standard IVF}

A process in which an egg is fertilised by sperm outside the body: in vitro. Own or donated gametes may be used.

Learn more at: www.fertilitypedia.org/edu/therapies/standard-ivf

\section{Surrogacy}

The embryo is gestated in a third party's (surrogate) uterus.

Learn more at: www.fertilitypedia.org/edu/therapies/surrogacy

\section{Traditional Chinese medicine}

A broad range of medicine practices sharing common concepts which have been developed in China and are based on a tradition of more than 2000 years.

Learn more at: www.fertilitypedia.org/edu/therapies/traditional-chinese-medicine

\section{Gallery}

\section{Calcified fibroids}

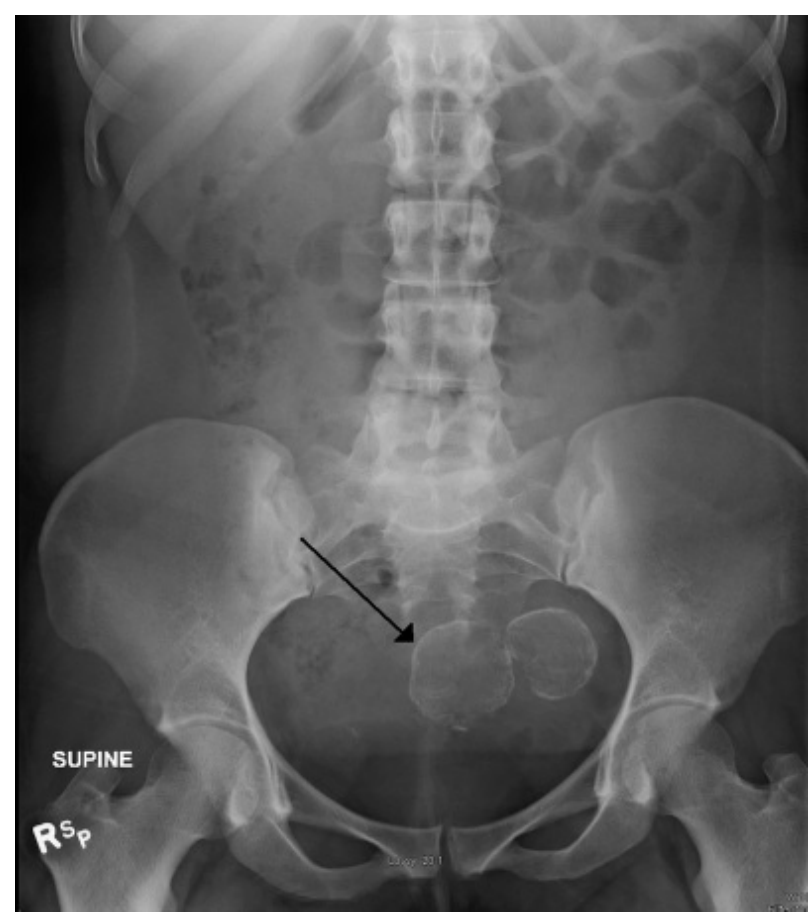

Fibroid of the uterus - computed tomography

(CT)

A very large $(9 \mathrm{~cm})$ fibroid of the uterus which is causing pelvic congestion syndrome as seen on CT.

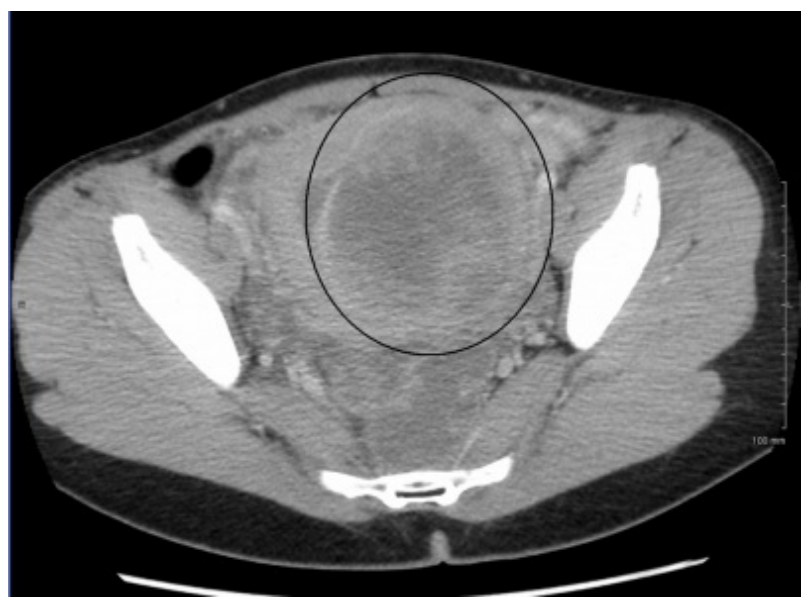

\section{Laparoscopic surgery of uterine fibroids}

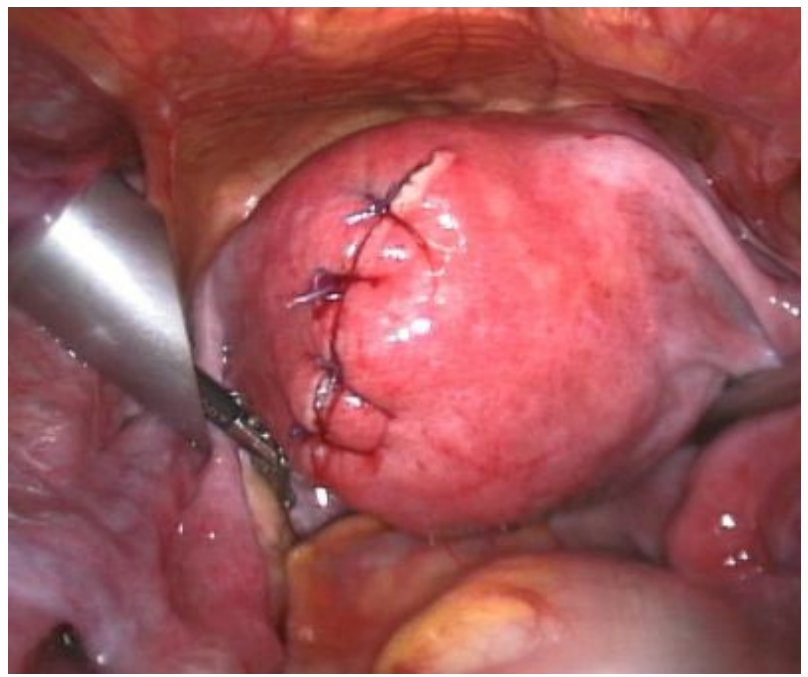




\section{Leiomyoma of the Uterus}

A relatively large submucosal leiomyoma; it fills out the major part of the endometrial cavity.

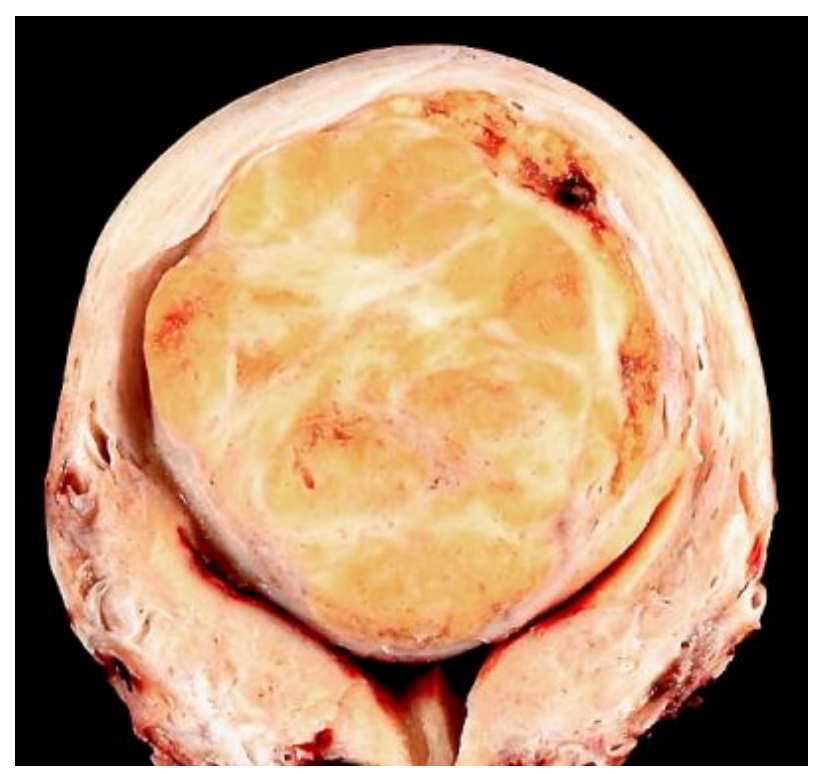

Myom

Large subserosal fibroid.

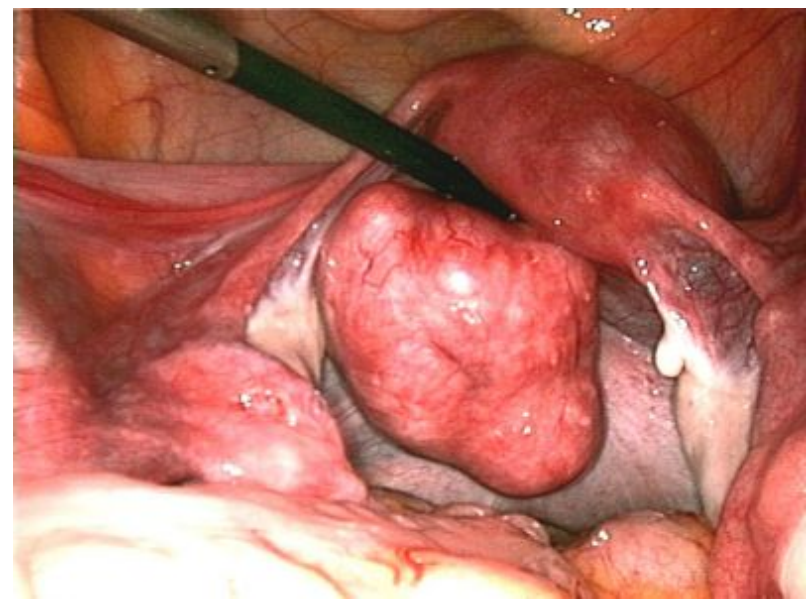

\section{Leiomyoma}

An enucleated uterine leiomyoma - external surface on left, cut surface on right.

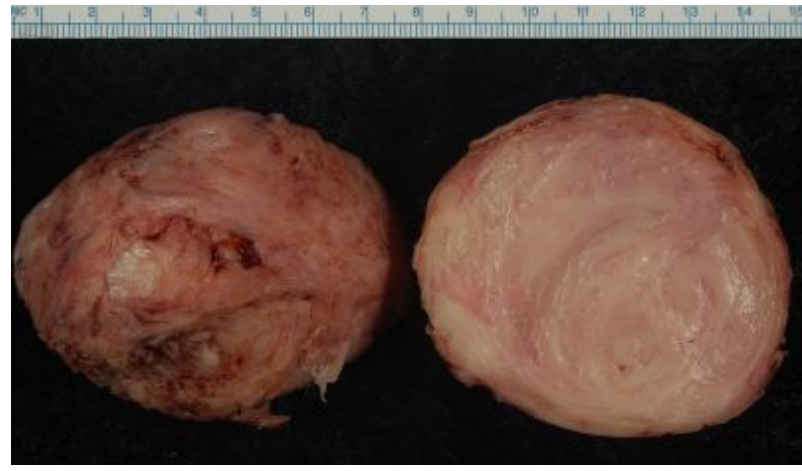

\section{Lipoleiomyoma}

Micrograph of a lipoleiomyoma, a type of leiomyoma.

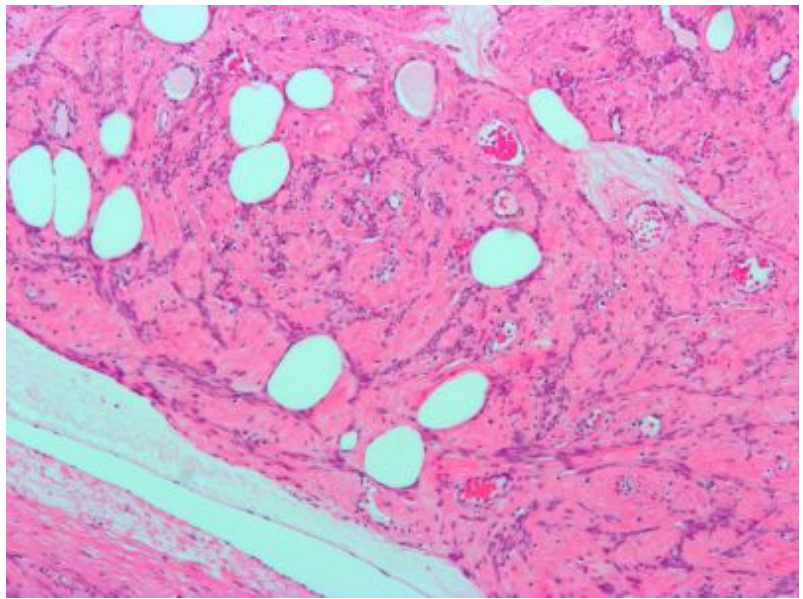

Pic

Mechanisms of action of progesterone receptor modulators on uterine fibroids.

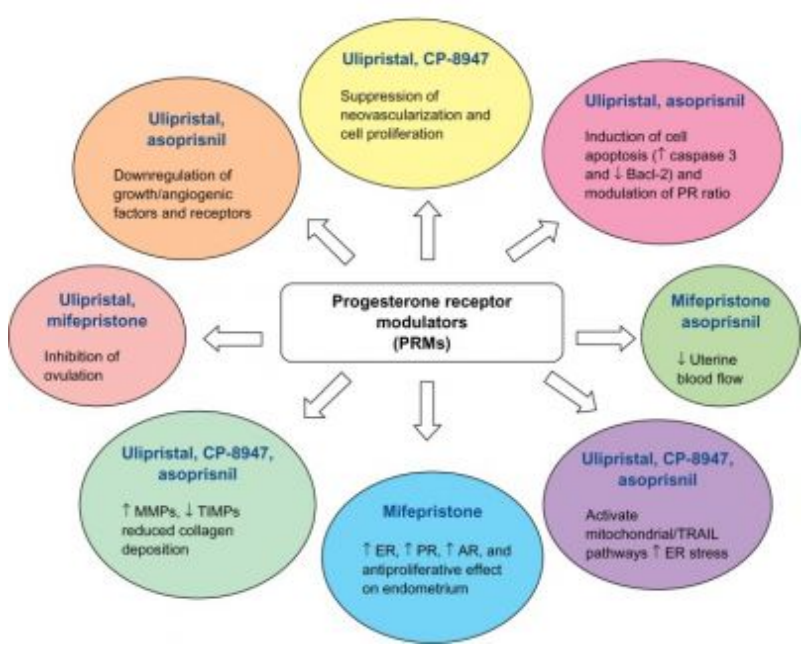




\section{Pic}

$B$-mode image $(A)$ in woman with a diagnosis of an endometrial polyp and corresponding strain image $(B)$. Red arrows indicate the location of the polyp, and yellow contours indicate the outer uterine wall.
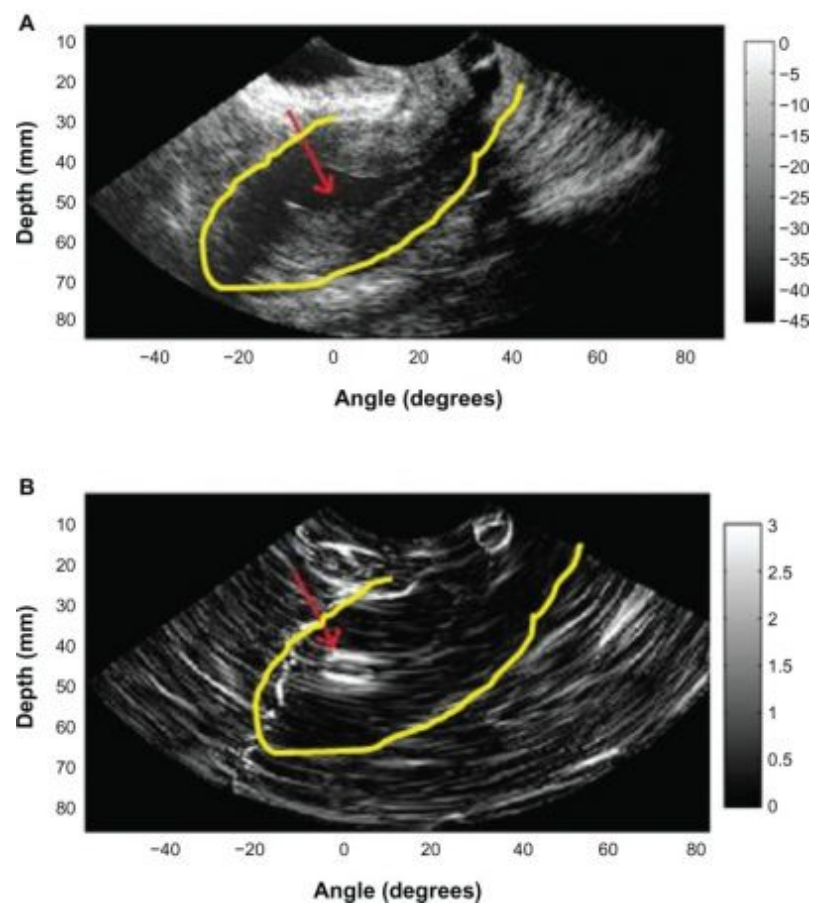

\section{Types of uterine fibroids}

Schematic drawing of various types of uterine fibroids: $a=s u b s e r o s a l$ fibroids, $b=$ intramural fibroids, c=submucosal fibroid, $d=$ pedunculated submucosal fibroid, e=fibroid in statu nascendi, $f=$ fibroid of the broad ligament

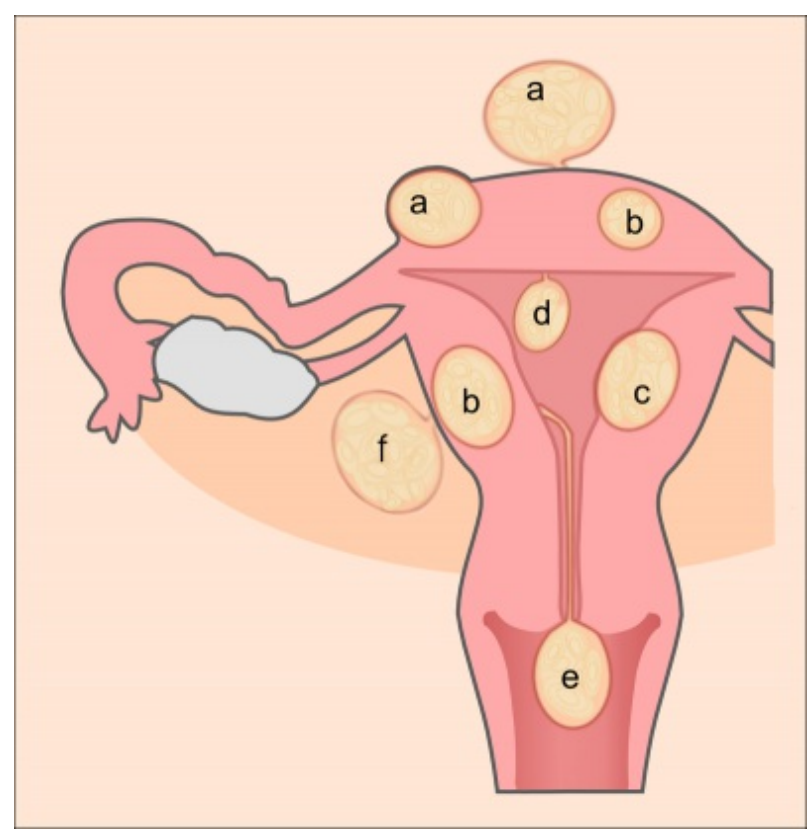

\section{Pic}

Transvaginal ultrasound image showed a bulky fibroid uterus with multiple intramural fibroids.

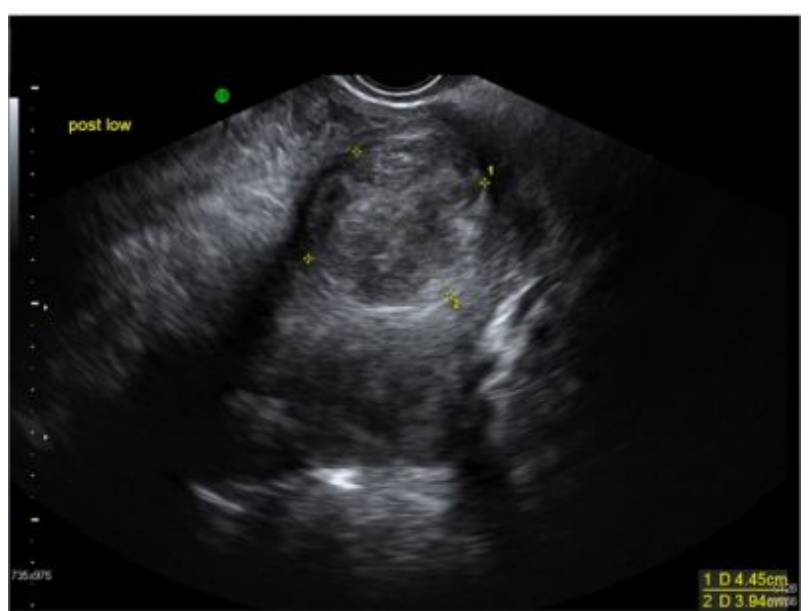




\section{Uterine fibroids}

Uterine fibroids as seen during laproscopic surgery.

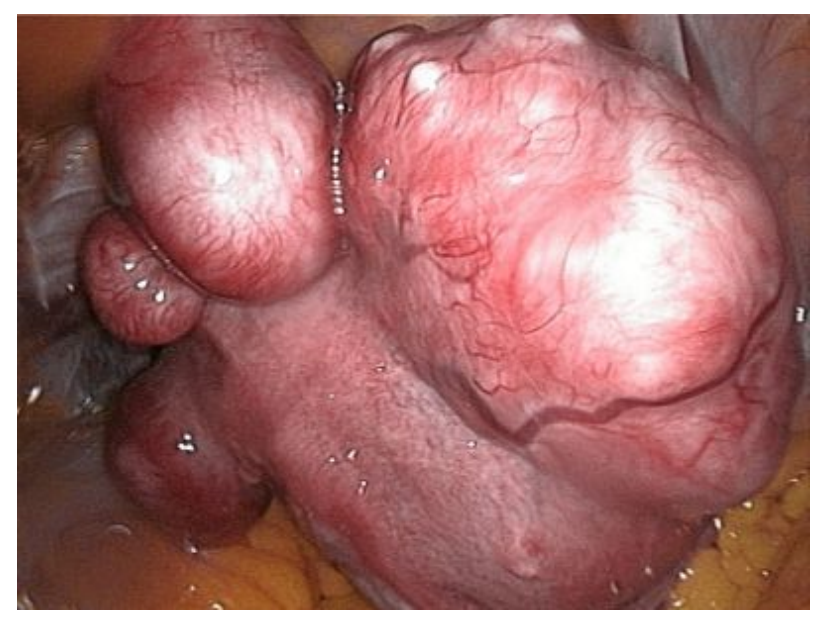

\section{Sources}

"Uterine_fibroids (https://en.wikipedia.org/wiki/Uterine fibroid\#/media/File:Uterine fibroids.jpg)" -by Hic et nunclicensed under CC BY-SA 3.0

"UTERINE FIBROID (http://worldheritage.org/article/WHEBN0001772647/Uterine\%20fibroid\#Diagnosis)" -sourced from World Heritage Encyclopedia licensed under CC BY-SA 3.0

"Uterine fibroids: current perspectives (https://www. dovepress.com/uterine-fibroids-current-perspectivespeer-reviewed-article-IJWH)" - by Khan et al. licensed under CC BY-NC 3.0

"Narcolepsy (https://en.wikipedia.org/wiki/Narcolepsy)" - sourced from Wikipedialicensed under CC BY-SA $\underline{3.0}$

" Complications of Uterine Fibroids and Their Management, Surgical Management of Fibroids, Laparoscopy and Hysteroscopy versus Hysterectomy, Haemorrhage, Adhesions, and Complications (http://www.hindawi.com/journals/ogi/2012/791248/)" - by Mettler et al. licensed under CC BY $\underline{3.0}$

"Unplanned pregnancy after ultrasound-guided percutaneous microwave ablation of uterine fibroids: A follow-up study (http://www.nature.com/articles/srep18924)" - by Bing-song et al. licensed under CC BY 4.0

"A Pearl for Uterine Fibroids (http://www.jpmsonline.com/jpms-vol2-issue3-pages120-121-na.html)" -by Chatterje and Pariharlicensed under CC BY-NC 3.0

"Uterine fibroids: Repeat myomectomy converted to supracervical hysterectomy. A case report and literature review. (https://www.webmedcentral.com/article view/4979)" -by Onyekalicensed under CC BY 3.0

" $9 \mathrm{~cm}$ Fibroid Pelvic

CongestionS (https://en.wikipedia.org/wiki/Uterine fibroid\#/media/File:9cmFibroidPelvicCongestionS.png)"

-by Heilman licensed under CC BY-SA 3.0

"Leiomyoma of the

Uterus (https://en.wikipedia.org/wiki/Uterine fibroid\#/media/File:Leiomyoma of the Uterus.jpg)" -by

Uthman licensed under $\underline{\mathrm{CCO}} 1.0$

“Leiomyoma (https://en.wikipedia.org/wiki/Uterine fibroid\#/media/File:Leiomyoma.jpg)" -by Uthman licensed under CC BY 2.0

“Lipoleiomyoma2 (https://en.wikipedia.org/wiki/Uterine fibroid\#/media/File:Lipoleiomyoma2.jpg)" -by Nephron licensed under CC BY-SA 3.0 
"Myom (https://en.wikipedia.org/wiki/Uterine fibroid\#/media/File:Myom.jpg)" - by Hic et nunclicensed under $\underline{\mathrm{CCO}} 1.0$

"Uterine fibroids.png (https://en.wikipedia.org/wiki/Uterine fibroid\#/media/File:Uterine fibroids.png)" -by Hic et nunclicensed under CC BY-SA 3.0

"Uterine fibroids (https://en.wikipedia.org/wiki/Uterine fibroid\#/media/File:Uterine fibroids.jpg)" -by Hic et nunclicensed under CC BY-SA 3.0 